Table 1 Consumption of analgesics (numbers of boxes each containing 20 pills) by patients with analgesic tolerant asthma and analgesic induced asthma $(A I A)$

\begin{tabular}{|c|c|c|c|c|c|c|}
\hline \multirow[b]{2}{*}{ Analgesic } & \multicolumn{3}{|c|}{ Asthma $(n=103)$} & \multicolumn{3}{|l|}{$A I A(n=191)$} \\
\hline & Mild $+(n=56)$ & Moderate $(n=43)$ & Severe $(n=4)$ & Mild $(n=68)$ & Moderate $(n=97)$ & Severe $(n=26)$ \\
\hline Aspirin & $2.3(5.3)$ & $4.3(11.3)$ & $0.13(0.3)$ & $4.2(9.9)$ & $3.8(6.5)$ & $4.3(6.4)$ \\
\hline Metamizole & $1.9(4.4)$ & $4.0(7.9)$ & $0.5(1.0)$ & $2.3(5.3)$ & $1.9(3.4)$ & $2.7(3.3)$ \\
\hline Paracetamol & $1.6(2.1)$ & $2.6(5.0$ & $1.9(1.9)$ & $3.7(7.3)^{\star}$ & $4.4(10.6)^{\star}$ & $3.2(4.5)^{\star}$ \\
\hline $\begin{array}{l}\text { Total analgesic } \\
\text { consumption }\end{array}$ & $7.0(11.8)$ & $12.4(15.8)^{\star}$ & $2.8(0.9)$ & $11.8(14.5)^{\star}$ & $12.3(16.5)^{\star}$ & $12.5(11.6)^{\star}$ \\
\hline
\end{tabular}

\title{
†Reference group.
}

${ }^{\star} \mathrm{p}<0.05$.

${ }^{\star}$ Other analgesics not included.

would be interested to hear of similar problems that have been encountered with this device or other chest drain systems in which there is an occluding cap.

J A CORLESS $M$ BARBORES $S$ DONOGHUE

$M$ G PEARSON

M G PEARSON
R W COSTELLO Aintree Chest Centre,

University Hospital Aintree, Liverpool L9 7AL, UK johncorless@hotmail.com

Correspondence to: Dr M G Pearson.

\section{Paracetamol and asthma}

We were interested to read the article by Shaheen et al on the relationship between paracetamol and asthma. ${ }^{1}$ We have been interested in patients with analgesic induced asthma (AIA) since 1991 and now have a total of about 238 patients who have been followed up in our allergy unit. We have previously reported some related allergic conditions and risk factors for AIA, one of which was cumulative life long analgesic consumption. ${ }^{2-4}$ After reading the paper by Shaheen et al we re-analysed our data and compared the consumption of analgesics by patients with analgesic tolerant asthma (group 1, $\mathrm{n}=103$ ) and those with AIA (group $2, \mathrm{n}=191$ (132 published $^{2}+59$ new cases)). The mean ages of the patients were 43.1 (14.0) years and 40.9 (12.3) years and there were $89(86.4 \%)$ and $140(73.3 \%)$ women in groups 1 and 2, respectively. The life long analgesic consumption was evaluated by a question included in the standard questionnaire about the number of boxes of analgesics used before analgesic intolerance was diagnosed (each box contains 20 pills).

There was no significant difference between the two groups in the total consumption of analgesics (9.1 (12.5) $v 12.1$ (15.1)), aspirin (5.1 (10.3) $v 4.4(8.1))$, metamizole (4.9 (7.5) v $3.3(4.8)$ ), and paracetamol (3.5 (4.1) $v 5.1(9.8))$. The independent samples $t$ test was used to compare the severity of asthma and the amount of analgesic consumption and the total analgesic and paracetamol consumption was found to be significantly higher in AIA patients with mild, moderate and severe asthma than in those with mild analgesic tolerant asthma (table 1). However, the correlation between the severity of asthma and the consumption of analgesics (overall, aspirin, metamizole, paracetamol) was not significant in either group when
Spearman's non-parametric correlation test was applied to the data.

It is already known that the clinical course of patients with AIA is more severe than for those with analgesic tolerant asthma, and the overall consumption of analgesics and paracetamol by AIA patients has been found to be higher. ${ }^{2}$ It should also be added that the increased consumption of paracetamol in these patients results from physicians' analgesic preference and our re-analysis showed a weak relation. Certainly the clinical and epidemiological surveys should be evaluated separately, but our results seem to support the results of Shaheen et al. ${ }^{1}$ Since these retrospective surveys might include "recall bias", prospective studies of asthma patients could help to elucidate the difference between the analgesic consumption of patients with AIA and those without analgesic intolerance.

G KARAKAYA A U DEMIR A F KALYONCU Hacettepe University Hospital, Department of Chest Diseases, Adult Allergy Unit, 06100 Sihhiye, Ankara,

Turkey

1 Shaheen SO, Sterne JAC, Songhurst CE, et al. Frequent paracetamol use and asthma in adults. Thorax 2000;55:266-71.

2 Kalyoncu AF, Karakaya G, Şahin AA, et al. Occurrence of allergic conditions in asthmatics with analgesic intolerance. Allergy 1999;54: 428-35.

3 Karakaya G, Demir AU, Kalyoncu AF. Is there an association between bronchial asthma, food an association between bronchial asthma, food allergy/intolerance and ana

4 Karakaya G, Demir AU, Kalyoncu AF. From Karakaya G, Demir AU, Kalyoncu AF. From asthma: are there some determinants? Allergo Immunopathol 2000;28:229-37.

\section{BOOK REVIEW}

High Altitude Medicine and Physiology. 3rd Edition. M P Ward, J S Milledge, J B West. (Pp 434, hardback; £69.00). London: Arnold, 2000. 0340759801

This is the third edition of the standard textbook on high altitude medicine. Although it is only five years since the second edition appeared, the book has been extensively revised to take into account the recent explosion of interest in high altitude medicine. As the authors mention in their preface to the third edition, there have been over 1500 publications since 1995 on altitude related topics. All the chapters in this edition have been updated to take into account these recent publications and additional sections on commercial activities at altitude have been added.

I was interested to receive this new edition because, by chance, the first edition of this book was the first medical textbook I ever bought. At the time I was a student planning a trip to the Himalayas and wanted to learn more about the aetiology of the life threatening forms of acute mountain sickness, high altitude pulmonary oedema, and high altitude cerebral oedema. The book provided an excellent overview of the subject and introduced me to other interesting topics. Comparing the first and third editions, it is interesting to note that relatively little advance has been made in terms of understanding the pathophysiology of high altitude pulmonary and/or cerebral oedema, despite their increasing importance given the greater numbers of individuals travelling to high altitude now compared with 20 years ago. Those advances which have been made are well summarised in the relevant chapters of the third edition.

High Altitude Medicine and Physiology remains the standard textbook in its subject area. It is comprehensive and well referenced and yet remains eminently readable. This is not a handbook of emergency medicine for the use of doctors or mountaineers travelling to altitude, but a book which covers a much broader subject area. It should be on the bookshelves of all individuals interested in the effect of altitude on the human body.-IH

\section{NOTICE}

\section{Respiratory Medicine}

A conference on Respiratory Medicine will be held at the Royal College of Physicians of Edinburgh on 26 October 2001. For further information contact Ms Eileen Strawn, Symposium Coordinator. Telephone 0131225 7324. Fax 0131220 4393. Email: e.strawn@rcpe.ac.uk. Website: www.rcpe.ac.uk. 